\title{
Sucrose and inverted sugar as plasticizer. Effect on cassava starch-gelatin film mechanical properties, hydrophilicity and water activity
}

\author{
P. Veiga-Santos ${ }^{\text {a,* }}$, L.M. Oliveira ${ }^{\text {b }}$, M.P. Cereda ${ }^{c}$, A.R.P. Scamparini ${ }^{d}$ \\ a POLI-UFBA, 40210-730, Salvador, BA, Brazil \\ ${ }^{\mathrm{b}}$ CETEA-ITAL, P.O. Box 139, 13073-001, Campinas, SP, Brazil \\ ${ }^{\mathrm{c}}$ CeTeAgro-UCDB, 79117-900, Campo Grande, MS, Brazil \\ d DCA-FEA-UNICAMP, P.O. Box 6121, 13081-970, Campinas, SP, Brazil
}

Received 14 February 2006; received in revised form 12 April 2006; accepted 28 July 2006

\begin{abstract}
The effect of sucrose and inverted sugar as plasticisers on mechanical properties, hydrophilicity and water activity of cassava starch films has been studied. Other additives (gelatin, soybean oil, sodium phosphate and propylene glycol) and pH effect have also been investigated, using the same parameters. Sucrose addition resulted in the highest effect observed on cassava starch films elongation at break, however inverted sugar also had a great effect on this property. The addition of plasticiser and acidic $\mathrm{pH}$ increased film water absorption kinesis, while cassava starch concentration had the opposite effect.
\end{abstract}

(C) 2006 Elsevier Ltd. All rights reserved.

Keywords: Bio-based films; Additives; Plasticizer; Characterization

\section{Introduction}

Starch is considered one of the most promising natural polymers for packaging applications (Krochta and Mulder-Johnston, 1997) because of its low cost, renewability and biodegradability (Avérous, Fringant, \& Moro, 2001). Unfortunately, starch-based products have some major limitations when compared to conventional petroleum films, due to their poor mechanical properties (Martin, Schwach, Avérous, \& Couturier, 2001). To overcome such disadvantages, with additives (Coupland, Shaw, Monahan, O'riordan, \& O'sullivan, 2000; Garcia, Martino, \& Zaritzki, 2000), such as sucrose, are recommended (Arvanitoyannis, Psomiadou, \& Nakayama, 1996).

Sucrose addition to cassava starch films has increased elongation at break of starch-xanthan gum films (Veiga-

\footnotetext{
${ }^{*}$ Corresponding author. Tel.: +55 713203 9700; fax: +55 1132039712.

E-mail address: priveiga@yahoo.com.br (P. Veiga-Santos).
}

Santos, Oliveira, Cereda, Alves, \& Scamparini, 2005), although crystallinity was observed during storage, changing the material from malleable to brittle (Veiga-Santos, Suzuki, Cereda, \& Scamparini, 2005).

Sucrose, which is a disaccharide, can be broken down into a 1:1 mixture of dextrose (glucose) and laevulose (fructose), known as invert sugar (Jackson, 1995). Inverted sugar has a lower tendency to crystallize, when compared to sucrose (Jackson, 1995), and is also considered a lowcost product. It is frequently used in the food industry to reduce sucrose crystallisation in high viscosity solutions, compared to solutions containing sucrose alone. While sucrose itself is saturated at $67 \%$ solids, a $50 / 50$ mixture with invert sugar becomes saturated at $76 \%$ solids (Jackson, 1990).

The substitution of sucrose with invert sugar may prevent the crystallization process. Also for a country such as Brazil, that has produced 411 million tons of cane sugar in 2004 (FAOSTAT, 2005), the substitution of sucrose for 
invert sugar, a sugar cane by-product, represents a relevant economic opportunity.

Gelatin is another low-cost and abundant raw material. It may improve biodegradable film mechanical properties (Arvanitoyannis, Psomiadou, Nakayama, Aiba, \& Yamamoto, 1997) and has shown compatibility with plasticisers (Vanin, Sobral, Menegalli, Carvalho, \& Habitante, 2005).

Some other frequently used additives, such as propylene glycol (Lacroix, Jobin, Mezgheni, Srour, \& Boileau, 1998) and sodium phosphate (Mezgheni, Vachon, \& Lacroix, 2000), can be used to improve starch film mechanical properties. To improve hydrophobicity, additives such as soybean oil have been used (Garcia et al., 2000; Yang \& Paulson, 2000).

Although gelatin has been widely used as an additive (Arvanitoyannis et al., 1997; Lee, Shim, \& Lee, 2004; Vanin et al., 2005), few studies have been performed on the effect of gelatin on a multi-component starch matrix film containing sucrose (or invert sugar) and other additives. Analysing the same additives as investigated in a previous work (propylene glycol, sodium phosphate and soybean oil) (Veiga-Santos, Oliveira et al., 2005; Veiga-Santos, Suzuki et al., 2005) allows the performance of cassava starch-gelatin films to be compared with results obtained for cassava starch-xanthan gum films.

With the aim of investigating the possibility of substituting sucrose with invert sugar as an additive for biodegradable films, a factorial experimental design was performed. This substitution effect on cassava starch-gelatin films tensile strength, elongation at break, contact angle measurement and moisture content was evaluated. The same parameters were also investigated to evaluate the effect of possible interactions between sucrose (or invert sugar) and starch-gelatin multi-component films (gelatin plus propylene glycol, sodium phosphate and soybean oil). A cassava starch film containing no other additives was also formulated as a control film.

\section{Material and methods}

\subsection{Materials}

Commercial cassava starch (Flor de Lotus, Brazil), inverted cane sugar (Copersucar União, São Paulo Brazil), gelatin type B (Liner Davis Gelatin, Brazil) and soybean oil (Cargill Agricola S.A., São Paulo Brazil) were purchased, along with analytically pure sucrose, propylene glycol and monobasic sodium phosphate (Sinth, Brazil).

\subsection{Sample preparation}

Cassava starch $(3-5 \%, \mathrm{w} / \mathrm{w})$ was blended with sucrose or invert sugar $(0-2 \%, \mathrm{w} / \mathrm{w})$, propylene glycol $(0-1 \%, \mathrm{w} / \mathrm{w})$, sodium phosphate $(0-0.2 \%, \mathrm{w} / \mathrm{w})$ and soybean oil $(0-0.06 \%$, w/w), in aqueous solution. Gelatin $(0-0.7 \%$, $\mathrm{w} / \mathrm{w})$ was dispersed in distilled water $\left(100^{\circ} \mathrm{C}\right)$, cooled to
$40{ }^{\circ} \mathrm{C}$ and added to the previously blended ingredients. The $\mathrm{pH}$ was adjusted ( $\mathrm{pH} 4-8)$ with $50 \%$ citric acid solution or $5 \%$ sodium hydroxide solution and heated to $75^{\circ} \mathrm{C}$ with constant stirring, to obtain starch gelatinisation. The cassava starch films were prepared using the casting technique, by dehydration under renewable circulated air $\left(30 \pm 2{ }^{\circ} \mathrm{C}\right)$ over polystyrene Petri dishes. Films containing only cassava starch (no additives or $\mathrm{pH}$ adjustment) served as the control. Samples were stored $\left(23{ }^{\circ} \mathrm{C}, 75 \% \mathrm{RH}\right)$ for at least 4 days prior to testing.

Since starch films have a hydrophilic character (Avérous, Moro, Dole, \& Fringant, 2000), 75\% relative humidity was chosen to condition the experimental films, in order to evaluate the material performance in a high moisture environment. Such a humidity value is appropriate for a tropical country such as Brazil.

\subsection{Mechanical properties}

The tensile strength and elongation at break of the films were measured using an Instron Universal Testing Instrument (model 5500R Barueri Brazil), operated as specified in ASTM standard method D882-00 (ASTM, 2001; Veiga-Santos, Oliveira et al., 2005; Veiga-Santos, Suzuki et al., 2005). Tested film strips $(8 \times 2.5 \mathrm{~cm})$ were cut from each preconditioned $\left(75 \% \mathrm{RH}, 23{ }^{\circ} \mathrm{C}\right)$ sample and mounted between the grips of the machine. The thickness of each specimen was measured at four points along its length with a Mitutoyo digital micrometer (AMI, Painesville, OH). Initial grip separation and crosshead speed were set to $50 \mathrm{~mm}$ and $12.5 \mathrm{~mm} / \mathrm{min}$, respectively. Ten specimens were tested for each sample. The sample's tensile strength $(\Delta T \%)$ and elongation at break $(\Delta E \%)$ were calculated relative to the control were calculated using equations 1 and 2, respectively:

$$
\begin{aligned}
& \Delta T=\left[\left(\frac{\text { sample tensile strength }}{\text { control tensile strength }}\right) \times 100\right]-100 \\
& \Delta E=\left[\left(\frac{\text { sample elongation }}{\text { control elongation }}\right) \times 100\right]-100
\end{aligned}
$$

Preconditioned $\left(75 \% \mathrm{RH}, 23{ }^{\circ} \mathrm{C}\right)$ stretch polyvinyl chloride $(\mathrm{PVC})$ film strips $(8 \times 2.5 \mathrm{~cm})$ were also evaluated under the same conditions and used as a reference for mechanical comparison parameters.

\subsection{Moisture content}

Moisture content of each preconditioned sample $(75 \%$ $\mathrm{RH}, 23{ }^{\circ} \mathrm{C}$ ) was determined after $24 \mathrm{~h}$ of drying at $105^{\circ} \mathrm{C}$ (Pouplin, Redl, \& Gontard, 1999).

\subsection{Contact angle measurement}

The contact angle measurements were determined using a VCA Optima Surface Analysis System (AST Products Inc., Billerica, MA) to evaluate the hydrophilic feature of the 
samples (Avérous \& Fringant, 2001). The evolution of the water drop $(3 \times 10 \mathrm{ml})$ shape on the surface of preconditioned $\left(75 \% \mathrm{RH}, 23{ }^{\circ} \mathrm{C}\right) 4 \mathrm{~cm}^{2}$ samples was recorded (in duplicate), to determine the material absorption kinesis (for $5 \mathrm{~min}$ ) Veiga-Santos, Oliveira et al., 2005; Veiga-Santos, Suzuki et al., 2005. The initial contact angle measurements just after deposition indicate the material hydrophilicity behaviour. In order to illustrate the absorption kinesis, the slope at the origin $(\% \mathrm{~min})$ was also calculated by linear regression from the points of the contact angle versus time (Avérous et al., 2000).

\subsection{Total starch, amylose and amylopectin content}

The cassava starch amylose and total starch content were evaluated according to ISO-6647 for starch materials (International Organization for Standardization, 1987). The amylopectin content was calculated by subtracting the amylose percentage from the total starch content.

\subsection{Statistical analysis}

Two blocks of a $2^{7-3}$ experimental factorial design were performed in order to select additives and process parameters that significantly $(p \leqslant 0.05)$ influenced cassava starch film mechanical properties, hydrophilicity and moisture content. The blocks were designed with three central points, totalling 19 experiments per block, differing in only one variable (sucrose or invert sugar concentration). The other variables were cassava starch, sucrose, soybean oil, sodium phosphate, propylene glycol and $\mathrm{pH}$ (Table 1).

The influence of the independent variables (at 95\% confidence interval) was evaluated by the Pareto chart of standardised effect, considering the ANOVA pure error. The experimental data were generated and analysed using Statistica for Windows software, version 5.0. The experimental design demonstrated in Table 2 was used to estimate the main effects of the independent variables.

Table 1

Coded independent variables and real values for the sucrose (S) and invert sugar (I) factorial experiment blocks, considering the total weight of the filmforming suspension

\begin{tabular}{llllll}
\hline Symbol & Variables & & Levels & \\
\cline { 2 - 3 } & Block-S & Block-I & -1 & 0 \\
\hline A & Sodium phosphate (\%) & Sodium phosphate (\%) & 0.00 & 0.35 \\
B & pH & pH & 4.00 & 6.00 & 0.70 \\
C & Cassava starch (\%) & Cassava starch (\%) & 3.00 & 4.00 & 8.00 \\
D & Sucrose (\%) & Invert sugar (\%) & 0.00 & 1.00 & 0.00 \\
E & Propylene glycol (\%) & Propylene glycol (\%) & 0.00 & 0.25 & 0.00 \\
F & Soybean oil (\%) & Soybean oil (\%) & 0.00 & 0.03 & 0.06 \\
G & Gelatin (\%) & Gelatin (\%) & 0.00 & 0.35 & 0.70 \\
\hline
\end{tabular}

Table 2

$2^{7-3}$ factorial design with coded (and concentration w/w\%) values for the film forming composition of the sucrose (S) and invert sugar (I) blocks

\begin{tabular}{|c|c|c|c|c|c|c|c|c|}
\hline \multicolumn{2}{|l|}{ Assays } & \multicolumn{7}{|l|}{ Variables } \\
\hline Block-S & Invert-I & $A$ & $B$ & $C$ & $D$ & $E$ & $F$ & $G$ \\
\hline S-1 & I-1 & $-1(0.00)$ & $-1(4.0)$ & $-1(3.0)$ & $-1(0.0)$ & $-1(0.00)$ & $-1(0.00)$ & $-1(0.00)$ \\
\hline $\mathrm{S}-2$ & $\mathrm{I}-2$ & $+1(0.70)$ & $-1(4.0)$ & $-1(3.0)$ & $-1(0.0)$ & $+1(0.50)$ & $-1(0.00)$ & $+1(0.70)$ \\
\hline$S-3$ & $\mathrm{I}-3$ & $-1(0.00)$ & $+1(8.0)$ & $-1(3.0)$ & $-1(0.0)$ & $+1(0.50)$ & $+1(0.06)$ & $-1(0.00)$ \\
\hline S-4 & $\mathrm{I}-4$ & $+1(0.70)$ & $+1(8.0)$ & $-1(3.0)$ & $-1(0.0)$ & $-1(0.00)$ & $+1(0.06)$ & $+1(0.70)$ \\
\hline S-5 & $\mathrm{I}-5$ & $-1(0.00)$ & $-1(4.0)$ & $+1(5.0)$ & $-1(0.0)$ & $+1(0.50)$ & $+1(0.06)$ & $+1(0.70)$ \\
\hline S-6 & I-6 & $+1(0.70)$ & $-1(4.0)$ & $+1(5.0)$ & $-1(0.0)$ & $-1(0.00)$ & $+1(0.06)$ & $-1(0.00)$ \\
\hline S-7 & $\mathrm{I}-7$ & $-1(0.00)$ & $+1(8.0)$ & $+1(5.0)$ & $-1(0.0)$ & $-1(0.00)$ & $-1(0.00)$ & $+1(0.70)$ \\
\hline $\mathrm{S}-8$ & $\mathrm{I}-8$ & $+1(0.70)$ & $+1(8.0)$ & $+1(5.0)$ & $-1(0.0)$ & $+1(0.50)$ & $-1(0.00)$ & $-1(0.00)$ \\
\hline S-9 & I-9 & $-1(0.00)$ & $-1(4.0)$ & $-1(3.0)$ & $+1(2.0)$ & $-1(0.00)$ & $+1(0.06)$ & $+1(0.70)$ \\
\hline S-10 & $\mathrm{I}-10$ & $+1(0.70)$ & $-1(4.0)$ & $-1(3.0)$ & $+1(2.0)$ & $+1(0.50)$ & $+1(0.06)$ & $-1(0.00)$ \\
\hline S-11 & $\mathrm{I}-11$ & $-1(0.00)$ & $+1(8.0)$ & $-1(3.0)$ & $+1(2.0)$ & $+1(0.50)$ & $-1(0.00)$ & $+1(0.70)$ \\
\hline S-12 & $\mathrm{I}-12$ & $+1(0.70)$ & $+1(8.0)$ & $-1(3.0)$ & $+1(2.0)$ & $-1(0.00)$ & $-1(0.00)$ & $-1(0.00)$ \\
\hline S-13 & $\mathrm{I}-13$ & $-1(0.00)$ & $-1(4.0)$ & $+1(5.0)$ & $+1(2.0)$ & $+1(0.50)$ & $-1(0.00)$ & $-1(0.00)$ \\
\hline S-14 & $\mathrm{I}-14$ & $+1(0.70)$ & $-1(4.0)$ & $+1(5.0)$ & $+1(2.0)$ & $-1(0.00)$ & $-1(0.00)$ & $+1(0.70)$ \\
\hline S-15 & $\mathrm{I}-15$ & $-1(0.00)$ & $+1(8.0)$ & $+1(5.0)$ & $+1(2.0)$ & $-1(0.00)$ & $+1(0.06)$ & $-1(0.00)$ \\
\hline S-16 & $\mathrm{I}-16$ & $+1(0.70)$ & $+1(8.0)$ & $+1(5.0)$ & $+1(2.0)$ & $+1(0.50)$ & $+1(0.06)$ & $+1(0.70)$ \\
\hline S-17@ ${ }^{a}$ & $\mathrm{I}-17 \bigodot^{\mathrm{a}}$ & $0(0.35)$ & $0(6.0)$ & $0(4.0)$ & $0(1.0)$ & $0(0.25)$ & $0(0.03)$ & $0(0.35)$ \\
\hline S-18( ${ }^{a}$ & $\mathrm{I}-18 \bigodot^{\mathrm{a}}$ & $0(0.35)$ & $0(6.0)$ & $0(4.0)$ & $0(1.0)$ & $0(0.25)$ & $0(0.03)$ & $0(0.35)$ \\
\hline $\mathrm{S}-19 \mathrm{I}^{\mathrm{a}}$ & $\mathrm{I}-19 \mathrm{I}^{\mathrm{a}}$ & $0(0.35)$ & $0(6.0)$ & $0(4.0)$ & $0(1.0)$ & $0(0.25)$ & $0(0.03)$ & $0(0.35)$ \\
\hline
\end{tabular}

${ }^{\mathrm{a}}$ Central points. 


\section{Results and discussion}

\subsection{Mechanical properties}

The additives and $\mathrm{pH}$ range tested in this study have affected cassava starch films' tensile strength (maximum resistance area) and elongation at break (Figs. 1 and 2, respectively). As clearly shown in Figs. 1 and 2, the experimental samples with sucrose (S-9 to S-19) and invert sugar (I-9 to I-19) added exhibited a very different behaviour from the other films. Results have also indicated that films

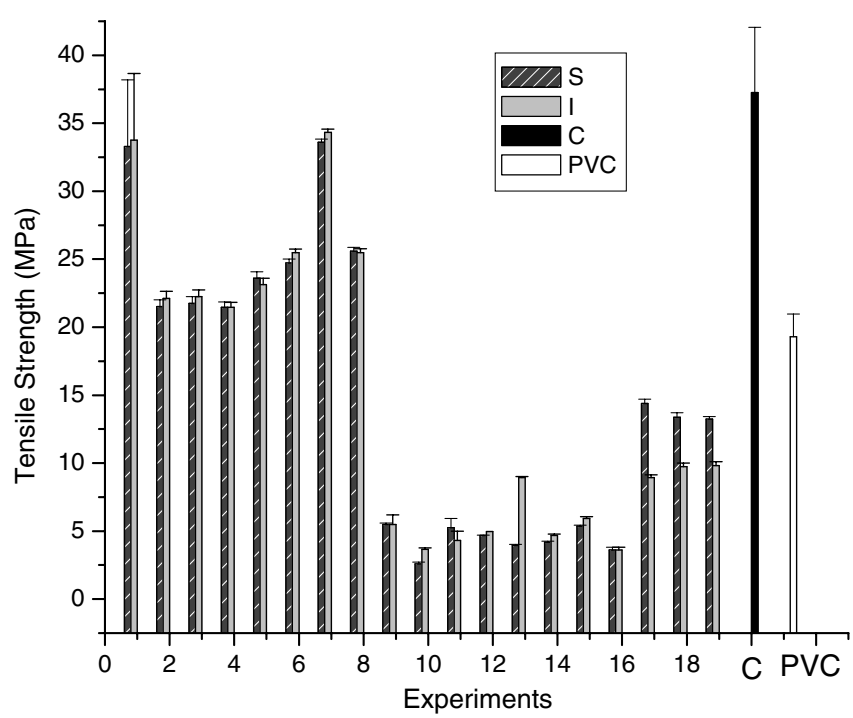

Fig. 1. Tensile strength measurements and standard deviations obtained for the sucrose (S) and invert sugar (I) experiments containing 19 assays for block, the control (C) film, and a stretch polyvinyl chloride (PVC) film.

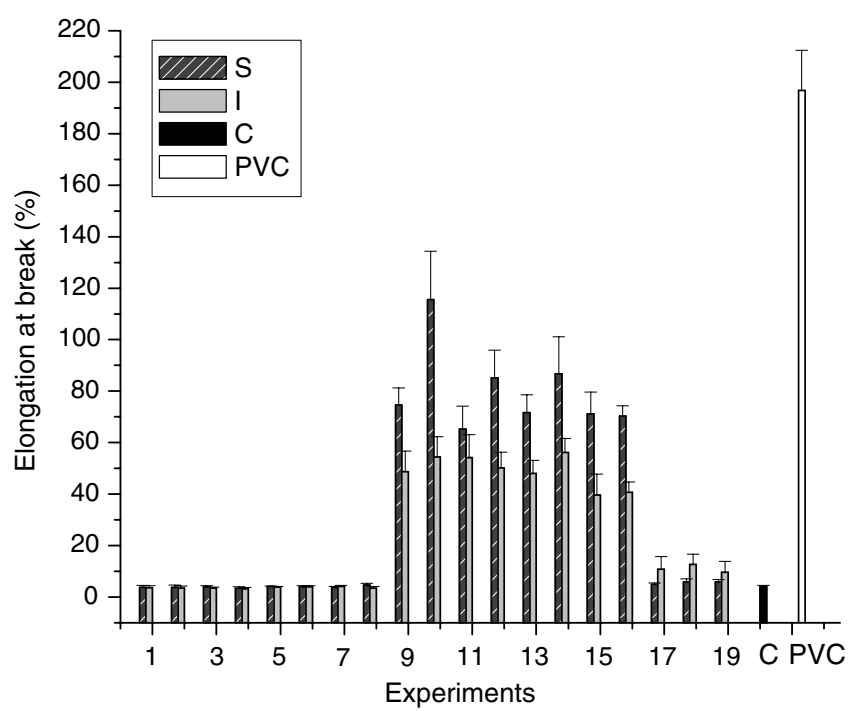

Fig. 2. Elongation at break measurements and standard deviations obtained for the sucrose (S) and invert sugar (I) experiments containing 19 assays for block, the control (C) film, and a polyvinyl chloride (PVC) film. containing $2 \%$ sucrose (S-9 to S-16) or invert sugar (I-9 to I-16) possessed the highest elongation at break (65.24$115.60 \%$ and $39.68-56.21 \%$, respectively). When compared to films with $1 \%$ sucrose (S-17 to S-19) or $1 \%$ invert sugar (I-17 to I-19) (5.54\% and $11.03 \%$, respectively), the results indicate that increasing the plasticiser concentration increases the cassava starch films' elongation at break.

Sucrose addition can increase elongation at break up to $2794 \%$, when compared to the control film. The invert sugar effect was lower, although significant $(1307 \%$, when compared to the control film). Such results indicate that sucrose is more efficient in increasing elongation at break than invert sugar.

The Pareto chart of standardized effect has confirmed that cassava starch films' elongation at break is positively $(p \leqslant 0.05)$ affected by sucrose and inverted sugar addition ( $R^{2}=0.85$ and 0.92 , respectively). The sucrose effect on elongation at break can also be observed through the visualisation of the elongation behaviour of samples when tensioned by tweezers, as shown in Fig. 3. Digital images of tensioned control film (containing just cassava starch) and sample S-12 (containing cassava starch plasticised with $2 \%$ sucrose $\mathrm{w} / \mathrm{w}$ ) were compared.

Sucrose plasticising effects on cassava starch films, resulting in a similar elongation at break increase $(2900 \%)$, were observed by Veiga-Santos et al. (2005). Arvanitoyannis et al. (1996) have also observed a plasticising effect for sucrose. According to Coupland et al. (2000), plasticiser agents reduce intermolecular forces and increase polymer chain mobility, thereby improving film flexibility and extensibility. The elongation increase observed when using invert sugar could also be attributed to a plasticising effect.

A similar effect to that observed in this study (3.99$115.6 \%$ ), for increasing elongation at break when adding sucrose as additive $(0-6 \%, \mathrm{w} / \mathrm{w})$, has also been reported (from $3.2 \%$ to $89.0 \%$ ) by Cheryan, Gennadios, Woller, and Chinachoti (1995), who also observed similar tensile strength values $(3.8-4.2 \mathrm{MPa})$ to those obtained in this study (2.58-14.4 MPa).

Although sucrose caused the most pronounced effect on elongation at break, sucrose-containing block (S) samples were also positively affected $(p \leqslant 0.05)$ by sodium phosphate and soybean oil, and negatively affected $(p \leqslant 0.05)$ by $\mathrm{pH}$, gelatin and cassava starch $\left(R^{2}=0.85\right)$.

The soybean oil effect on elongation at break can also be explained by its plasticising effect (Garcia et al., 2000). Also, the lipid's ability to form inclusion compounds with amylose (Belitz \& Grosch, 1999) could have resulted in a more flexible network, thus increasing the material elongation at break. Monobasic sodium phosphate can be added to starch to produce monoester phosphates, resulting in lower intermolecular association (BeMiller \& Whistler, 1996), which could explain the observed increase in elongation at break.

Decrease in elongation at break with higher gelatin concentration was also observed by Lee et al. (2004). The 

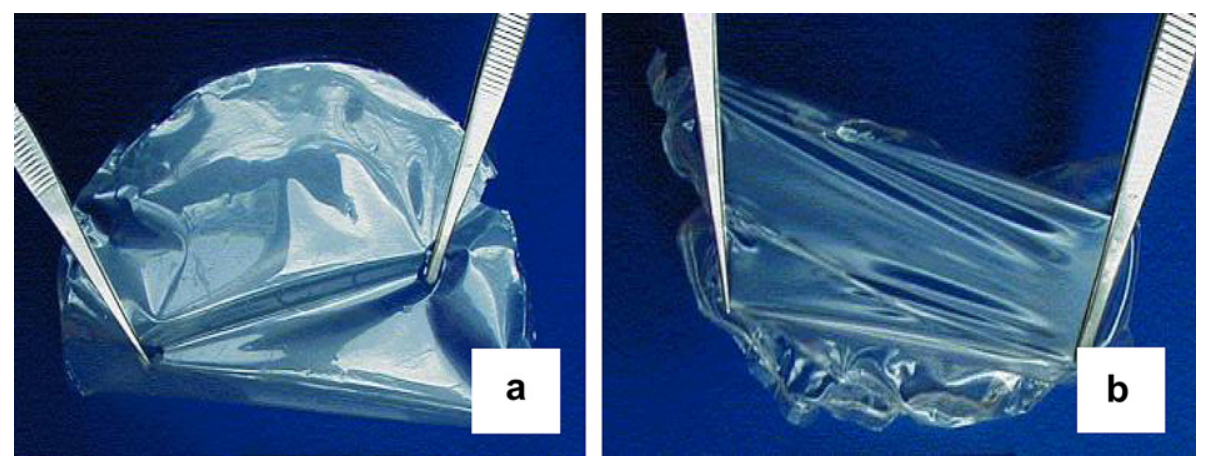

Fig. 3. Elongation behaviour of a cassava starch control (a) film and a sample plasticised with $2 \%$ sucrose (b).

authors attributed the observed reduction to a closely packed state in gelatin, where extensive intermolecular binding occurs, inhibiting both further reorientation and better alignment of the gelatin and starch chain.

The negative effect of $\mathrm{pH}$ on films' elongation at break can be attributed to the isoelectric point of gelatin type B. The acidic conditions evaluated in this study ( $\mathrm{pH} 4.0$ 6.0) were near the isoelectric point $(\mathrm{pH} 4.5-5.3)$ of gelatin type $\mathrm{B}$. While the net charge of gelatin at this $\mathrm{pH}$ is zero (Poppe, 1995), no interaction between gelatin and starch will occur. However, starch-gelatin interaction may occur by increasing $\mathrm{pH}$ away from the isoelectric point $(\mathrm{pH}$ 6.0-8.0), which could result in lower elongation at break, as discussed previously.

Protein-polysaccharide systems are characterized by limited compatibility between their components, occasionally resulting in phase separation. However, no double peak $(\tan \delta$ ) was observed in differential thermal analysis (DTA) thermograms for binary gelatin/starch blends, when evaluated as biodegradable film components. Such a result implies no phase separation (Arvanitoyannis et al., 1997), indicating possible interaction between starch and gelatin in a film matrix.

The negative effect of cassava starch concentration on film elongation at break can possibly be attributed to the amylopectin fraction, which for the cassava starch utilized in this study, represents $84 \%$. Amylopectin is a very branched molecule (BeMiller \& Whistler, 1996), which could lower the flexibility of the polymer network, consequently reducing film elongation at break.

For the sucrose-containing samples, the Pareto chart of standardised effect indicated significant $(p \leqslant 0.05)$ decrease in films' tensile strength when adding sucrose, propylene glycol, sodium phosphate and soybean oil.

For the invert sugar-containing (I) samples, the Pareto chart of standardized effect indicated a significant $(p \leqslant 0.05)$ decrease in films' tensile strength when adding the same additives (soybean oil, sodium phosphate, propylene glycol) and also invert sugar and gelatin. In addition, it indicated a significant $(p \leqslant 0.05)$ increase in films' tensile strength when increasing cassava starch concentration.

According to Coupland et al. (2000), an increase in plasticiser content can result in lower tensile strength resis- tance, which could explain the decrease in tensile strength when adding sucrose (Arvanitoyannis et al., 1996), propylene glycol (Kim, Ko, \& Park, 2002) and soybean oil (Garcia et al., 2000). Veiga-Santos et al. (2005) have already reported lower tensile strength in cassava starch films when adding sucrose, propylene glycol and soybean oil.

The negative effect on tensile strength observed when adding invert sugar, propylene glycol (Kim et al., 2002), soybean oil (Garcia et al., 2000) and gelatin (Arvanitoyannis, Nakayama, \& Aiba, 1998) can also be attributed to the plasticisation effect of such additives. The negative effect of propylene glycol and soybean oil on cassava-starch films' tensile strength has already been reported (Veiga-Santos, Oliveira et al., 2005; Veiga-Santos, Suzuki et al., 2005).

The negative effects of sodium phosphate on tensile strength can be attributed to interactions between sodium phosphate and starch that can produce monoester phosphates. The monoester starch exhibits lower intermolecular association, when compared to native starch (BeMiller \& Whistler, 1996), which could result in networks with lower tensile strength. Henrique (2002) also observed lower tensile strength for esterified cassava starch films, when compared to films formulated with native cassava starch.

Films formulated without the plasticisers sucrose or invert sugar, preconditioned at $75 \% \mathrm{RH}$, possessed similar tensile strength (from 21.5 to $34.3 \mathrm{MPa}$ ) and elongation at break (3.17-4.74\%) when compared to starch films (also without plasticisers) conditioned at $50 \% \mathrm{RH}(44.7 \mathrm{MPa}$ and $3.90 \%$, respectively) (Arvanitoyannis et al., 1996). Such results indicate that the high relative humidity utilised in this study $(75 \% \mathrm{RH})$ did not have a great impact on the material mechanical characteristics.

Comparing the control with a stretch PVC film analysed under the same conditions, the control film possessed higher tensile strength resistance (48.2\%) (Fig. 1), but lower elongation at break (-4833\%) (Fig. 2). Such results are in agreement with Veiga-Santos (2005), and indicated that the elongation at break is the least useful mechanical characteristic of cassava starch films, and efforts should be made to increase this property.

As expected, in general, the variables that increased elongation at break also decreased tensile strength. Also the individual effect of multi-component (cassava starch, 
gelatin, sodium phosphate, propylene glycol and sucrose or invert sugar) additives to the film may have been masked by their interaction, as the factorial experiment utilised in this work did not allow the evaluation of the effect of the interactions.

Among independent variables investigated in this work, sucrose, invert sugar, gelatin and cassava starch concentration have affected $(p \leqslant 0.05)$ the material thickness $\left(R^{2}=0.96\right)$, which ranged between 0.04 and $0.12 \mathrm{~mm}$ (Table 3). However, no correlation was observed between the mechanical property results and sample thickness. Such results indicate that, under the studied conditions, thickness did not affect, or had little effect on the material's mechanical properties.

Although the studied additives and $\mathrm{pH}$ modification have lowered the film tensile strength resistance (up to $-93.1 \%$ ), when compared to the control film, the observed increase in elongation at break when using sucrose (up to 2074\%) and invert sugar (up to 1308\%) (Fig. 3), justifies continuing the studies on such additives.

\subsection{Moisture content}

The experimental films' moisture contents for the sucrose and invert sugar-containing samples (between $13.1 \%$ and $18.4 \%$, and $13.2 \%$ and $18.4 \%$, respectively) were similar to that of the control $(13.5 \%)$ (Table 3$)$ and were not affected $(p<0.05)$ by any additive, $\mathrm{pH}$ modification or cassava starch concentration.

\subsection{Contact angle measurement}

The film hydrophilicity was quantitatively measured by the initial contact angle, and the water absorption kinesis was calculated by measurements of the slope at the origin $(\%$ min) (Table 3).

All samples possessed a very quick absorption, probably due to the hydrophilic nature of the cassava starch films (Avérous et al., 2000) and the additives (with the exception of soybean oil). Soybean oil, which has a hydrophobic character, did not influence $(p \leqslant 0.05)$ water absorption during time. Such result can be explained by the low soybean oil concentration $(<0.06 \%)$ used, in order to completely incorporate the lipid additive in the film network. Thus, a higher soybean oil concentration or an emulsifier should be used in order to affect cassava starch film hydrophilicity.

A Pareto chart of standardized effect has indicated that no additive or $\mathrm{pH}$ modification affected $(p \leqslant 0.05)$ the material hydrophilicity (evaluated by the initial contact angle measurement). However, the Pareto analyses indicated that, for the invert sugar (I) samples, the water absorption kinesis (during $5 \mathrm{~min})$ increased $(p \leqslant 0.05)$ with invert sugar addition and acidic $\mathrm{pH}$. It also indicated that water absorption kinesis decreased with cassava starch concentration. For the sucrose (S) samples, water absorption kinesis increased $(p \leqslant 0.05)$ with sucrose, propylene glycol and acidic $\mathrm{pH}$ and decreased $(p \leqslant 0.05)$ with cassava starch concentration. Such results indicate that invert

Table 3

Thickness (Tk) and water moisture content (M), initial contact angle (CA) and slope (\%min) for sucrose (S) and invert sugar (I) block samples

\begin{tabular}{|c|c|c|c|c|c|c|c|c|}
\hline \multirow[t]{2}{*}{ Assays } & \multicolumn{4}{|c|}{ Sucrose block (S) } & \multicolumn{4}{|c|}{ Invert sugar block (I) } \\
\hline & $\mathrm{Tk}^{\mathrm{a}}$ & $M \%$ & $\mathrm{CA}\left({ }^{\circ}\right)$ & Slope & $\mathrm{Tk}^{\mathrm{a}}$ & $M \%$ & $\mathrm{CA}\left({ }^{\circ}\right)$ & Slope \\
\hline Control & 0.04 & 13.51 & 70.10 & -4.79 & & & & \\
\hline 1 & 0.04 & 18.22 & 69.50 & -5.18 & 0.04 & 18.22 & 70.90 & -4.93 \\
\hline 2 & 0.05 & 16.71 & 77.10 & -1.81 & 0.05 & 16.71 & 77.10 & -2.02 \\
\hline 3 & 0.05 & 18.38 & 71.20 & -8.55 & 0.05 & 18.38 & 71.20 & -7.98 \\
\hline 4 & 0.05 & 17.25 & 75.80 & -10.97 & 0.05 & 17.25 & 75.80 & -10.47 \\
\hline 5 & 0.10 & 15.01 & 85.90 & -7.40 & 0.10 & 15.01 & 85.90 & -6.77 \\
\hline 6 & 0.09 & 15.63 & 70.70 & -11.75 & 0.09 & 15.63 & 70.70 & -12.32 \\
\hline 7 & 0.08 & 15.71 & 93.60 & -19.03 & 0.08 & 15.71 & 93.60 & -17.49 \\
\hline 8 & 0.08 & 15.08 & 76.10 & -12.85 & 0.08 & 15.08 & 76.10 & -11.71 \\
\hline 9 & 0.09 & 15.63 & 77.70 & -5.57 & 0.07 & 15.53 & 73.30 & -4.71 \\
\hline 10 & 0.08 & 15.01 & 57.70 & -3.33 & 0.06 & 15.10 & 42.30 & -0.98 \\
\hline 11 & 0.08 & 15.08 & 87.40 & -7.03 & 0.06 & 15.12 & 57.40 & -5.28 \\
\hline 12 & 0.09 & 15.71 & 80.10 & -10.72 & 0.06 & 15.69 & 86.30 & -7.17 \\
\hline 13 & 0.12 & 13.46 & 64.00 & -5.97 & 0.09 & 13.36 & 56.50 & 0.98 \\
\hline 14 & 0.11 & 13.13 & 82.20 & -9.09 & 0.10 & 13.17 & 69.20 & -10.28 \\
\hline 15 & 0.11 & 14.01 & 61.30 & -9.13 & 0.10 & 14.10 & 74.30 & -2.52 \\
\hline 16 & 0.11 & 13.19 & 78.80 & -5.83 & 0.11 & 13.22 & 73.90 & -15.65 \\
\hline $17(\mathrm{c})^{\mathrm{b}}$ & 0.09 & 15.36 & 50.60 & 2.07 & 0.08 & 15.39 & 69.00 & -3.65 \\
\hline $18(\mathrm{c})^{\mathrm{b}}$ & 0.08 & 15.36 & 70.60 & 0.89 & 0.08 & 15.38 & 83.50 & -3.40 \\
\hline $19(\mathrm{c})^{\mathrm{b}}$ & 0.08 & 15.36 & 59.90 & 3.23 & 0.08 & 15.38 & 82.80 & -6.20 \\
\hline$R^{2 \mathrm{c}}$ & 0.97 & 0.77 & 0.50 & 0.38 & 0.96 & 0.81 & 0.58 & 0.68 \\
\hline
\end{tabular}

a Tk: thickness (mm).

${ }^{\mathrm{b}}$ Central points.

${ }^{c}$ Coefficient of determination of the ANOVA statistical analysis. 
sugar, sucrose and propylene glycol increased the water absorption kinesis, while cassava starch decreased the absorption kinesis.

Comparing the central point films of both blocks (S-17 to S-19 and I-17 to I-19), which differ only by sucrose or invert sugar addition, respectively, it can be observed that sucrose addition resulted in a slight increase (0.89-3.23\% $\mathrm{min}$ ) in the water absorption kinesis, when compared to the invert sugar addition $\left(-3.40\right.$ to $\left.-6.20^{\circ} / \mathrm{min}\right)$. Such a result indicates that substituting sucrose for invert sugar may result in materials with lower water absorption kinesis. However, the coefficient of determination for the sucrose samples was very low $\left(R^{2}=0.38\right)$ and, thus, more investigations should be performed.

The acidic $\mathrm{pH}$ could have inverted sucrose to glucose and fructose. However, as both sucrose and invert sugar sample water absorption were affected by acidic conditions similarly, the observed increase was due to starch depolymerisation. Hydrolysis of the glycosidic bonds may occur, resulting in smaller fragments (BeMiller \& Whistler, 1996). Such hydrolysis could create void spaces in the film network, which can explain the increase in water absorption at low $\mathrm{pH}$.

Biaopiotrowicz (2003) also observed hydrophilicity decrease when increasing starch concentration. According to the author, the starch gel surface attempted to maintain maximal hydrophobic character with polar domains formed by functional groups of D-glucose units. Higher starch concentration may increase the film surface hydrophobicity, which could decrease the water absorption kinesis of the material.

Other research investigating the effect of additives on starch films has shown a similar initial contact angle (39.9-73.6 ${ }^{\circ}$ (Demirgöz et al., 2000), (32-71º) (Avérous, Fauconnier, Moro, \& Fringant, 1999), when compared to the experimental measurements obtained $\left(42.30-93.60^{\circ}\right)$ (Table 3).

Previous work observed similar water absorption values $\left(-2.20\right.$ to $\left.-9.13^{\circ} / \mathrm{s}\right)$ for films with added sucrose, when compared to the investigated sucrose $(0.89$ to $-10.72 \%)$ and invert sugar $(0.38$ to $-15.65 \%$ s) samples. Lower water absorption values $(-2.02$ to $-4.20 \%$ s $)$ were observed for starch films added with glycerol as plasticizer (Avérous et al., 2000).

No correlation was observed between the initial contact angle or the slope at the origin measurements and the material thickness. Such results indicate that, for the conditions utilised in this study, neither hydrophilicity nor water absorption was affected by the material thickness.

\section{Conclusions}

This work has indicated that adding sucrose or invert sugar, results in cassava starch films with increased elongation at break. However, sucrose had a greater effect when compared to invert sugar. Invert sugar and sucrose, also increased the material water absorption kinesis. Gelatin and other commonly used additives, did not influence the mechanical characteristics of cassava starch films added with added sucrose or inverted sugar. Acidic $\mathrm{pH}$ and cassava starch concentrations affected the water absorption kinesis of the samples. Results have suggested that sucrose can be replaced with invert sugar as a cassava starch film plasticiser. However, the effect of such substitution on material microstructure during storage should be investigated.

\section{Acknowledgements}

The authors gratefully acknowledge CNPq and FAEPUNICAMP for the financial support and Ms. Joyce I. S. Florecio for water activity determinations. We also acknowledge the Brazilian Packaging Technology Centre (CETEA-ITAL) for the Instron Universal Testing Machine access and $3 \mathrm{M}$ Brazil for the contact angle VCA optima equipment access. We also acknowledge the Flor de Lotus Brazil, Copersucar União Brazil and Liner Davis Gelatin Brazil, for the donation of cassava starch, invert cane sugar and gelatin type $\mathrm{B}$, respectively.

\section{References}

Arvanitoyannis, I., Nakayama, A., \& Aiba, S. (1998). Edible films made from hydroxypropyl starch and gelatin and plasticized by polyols and water. Carbohydrate Polymers, 36, 105-119.

Arvanitoyannis, I., Psomiadou, E., \& Nakayama, A. (1996). Edible films made from sodium caseinate, starches, sugar or glycerol. Part 1. Carbohydrate Polymers, 31(2), 179-192.

Arvanitoyannis, I., Psomiadou, E., Nakayama, A., Aiba, S., \& Yamamoto, N. (1997). Edible films made from gelatin, soluble starch and polyols. Part 3. Food Chemistry, 60(4), 593-604.

ASTM. (2001). Standard test method for tensile properties of thin plastic sheeting D882-00. West Conshohocken, Pennsylvania, USA: American Society for Testing and Materials (1 CD Room).

Avérous, L., Fauconnier, N., Moro, L., \& Fringant, C. (1999). Blends of thermoplastic starch and polyesteramide: processing and properties. Journal of Applied Polymer Science, 76, 1117-1128.

Avérous, L., \& Fringant, C. (2001). Association between plasticized starch and polyesters: processing and performances of injected biodegradable systems. Polymer Engineering and Science, 41, 727-734.

Avérous, L., Fringant, C., \& Moro, L. (2001). Starch-based biodegradable material suitable for thermoforming packaging. Starch, 53(8), 368-371.

Avérous, L., Moro, L., Dole, P., \& Fringant, C. (2000). Properties of thermoplastic blends: starch-polycaprolactone. Polymer, 41, 4157-4167.

Belitz, H.-D., \& Grosch, W. (1999). Food chemistry (2nd ed.). Berlin: Springer, pp. 919.

BeMiller, J. N., \& Whistler, R. L. (1996). Carbohydrates. In O. R. Fennema (Ed.), Food chemistry (3rd ed., pp. 157-224). New York: Marcel Dekker Inc.

Biaopiotrowicz, T. (2003). Wettability of starch gel films. Food Hydrocolloids, 17(2), 141-147.

Cheryan, G., Gennadios, A., Woller, C., \& Chinachoti, P. (1995). Thermomechanical behavior of wheat gluten films: effect of sucrose, glycerin and sorbitol. Cereal Chemistry, 72(1), 1-6.

Coupland, J. N., Shaw, N. B., Monahan, F. J., O'riordan, E. D., \& O'sullivan, M. (2000). Modeling the effect of glycerol on the moisture sorption behavior of whey protein edible films. Journal of Food Engineering, 43(1), 25-30. 
Demirgöz, D., Elvira, C., Mano, J. F., Cunha, A. M., Piskin, E., \& Reis, R. L. (2000). Chemical modification o starch based on biodegradable polymeric blends: effects on water uptake, degradation behavior and mechanical properties. Polymer Degradation and Stability, 70, 161-170.

FAOSTAT Agricultural data. (2005). Agricultural production. Crops Primary. Food and Agriculture Organization of the United Nations. http://faostat.fao.org/faostat/ Accessed 00.12.05.

Garcia, M. A., Martino, M. N., \& Zaritzki, N. E. (2000). Lipid addition to improve barrier properties of starch-based films and coatings. Food Chemistry and Toxicology, 65(6), 941-947.

Henrique, C. M. (2002). Caracterização de filmes de féculas modificadas de mandioca como subsídios para a aplicação em pós-colheita de hortículas. PhD thesis. (pp. 142). Faculty of Agronomic Science São Paulo State University, UNESP: Botucatu, BR. (in Portuguese).

International Organization for Standardization. (1987). Norme Internationale. Suisse. 5 p. ISSO-6647.

Jackson, E. B. (1995). Sugar confectionary manufacture (2nd ed.). London, UK: Blackie Academic and Professional, pp 1-200.

Kim, K. W., Ko, C. J., \& Park, H. J. (2002). Mechanical properties, water vapor permeabilities and solubilities of highly carboxymethylated starch-based edible films. Journal of Food Science, 67(1), 218-222.

Krochta, J. M., \& Mulder-Johnston, C. (1997). Edible and biodegradable polymer films: Challenges and opportunities. Food Technology, 51(2), 61-73.

Lacroix, M., Jobin, M., Mezgheni, E., Srour, M., \& Boileau, S. (1998). Polymerization of calcium caseinate solutions induced by gamma irradiation. Radiation Physical Chemistry, 52(1-6), 223-227.
Lee, K. Y., Shim, J., \& Lee, H. G. (2004). Mechanical properties of gellan and gelatin composite films. Carbohydrate Polymers(2), 251-254.

Martin, O., Schwach, E., Avérous, L., \& Couturier, Y. (2001). Properties of biodegradable multilayer films based on plasticized wheat starch. Starch/Stärke, 53, 372-380.

Mezgheni, E., Vachon, C., \& Lacroix, M. (2000). Bacterial use of biofilms cross-linked by gamma-irradiation. Radiation Physics and Chemistry, 58, 203-205.

Poppe, J. (1995). Gelatin. In Alan Imesom (Ed.), Thickening and gelling agents for foods (2nd ed., pp. 144-168). London: Blackie Academic and Professional.

Pouplin, M., Redl, A., \& Gontard, N. (1999). Glass transition of wheat gluten plasticized with water, glycerol, or sorbitol. Journal of Agricultural and Food Chemistry, 47(2), 538-543.

Vanin, F. M., Sobral, P. J. A., Menegalli, F. C., Carvalho, R. A., \& Habitante, A. M. Q. B. (2005). Effects of plasticizers and their concentrations on thermal and functional properties on gelatin-based films. Food Hydrocolloids, 19, 899-907.

Veiga-Santos, P., Oliveira, L. M., Cereda, M. P., Alves, A. J., \& Scamparini, A. R. P. (2005). Mechanical properties, hydrophilicity and water activity of starch-gum films: effect of additives and deacetylated xanthan gum. Food Hydrocolloids, 19(2), 341-439.

Veiga-Santos, P., Suzuki, C. K., Cereda, M. P., \& Scamparini, A. R. P. (2005). Microstructure and color of starch-gum films: Effect of gum deacetylation and additives. Part 2. Food Hydrocolloids, 19(6), 1064-1073.

Yang, L., \& Paulson, A. T. (2000). Effects of lipids on mechanical and moisture barriers properties of edible gellan film. Food Research International, 33, 571-578. 